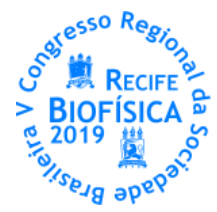

\title{
APLICAÇÕES TERAPÊUTICAS DOS RADIOFÁRMACOS: UM ESTUDO DA ARTE
}

\author{
Nathalia Maria Guedes ${ }^{1 *}$, Macius Vinícius Almeida Marques², Maria Luiza Carneiro Moura Gonçalves \\ Filiação: ${ }^{1}$ Farmácia, Centro Universitário Brasileiro, UNIBRA; ${ }^{2}$ Engenharia Civil, Escola Politécnica de Pernambuco, UPE \\ *nathaliamariaguedes@gmail.com
}

\begin{abstract}
INTRODUÇÃO
A medicina nuclear desempenha um papel fundamental na terapêutica, diagnóstico e investigação de doenças. Isto é resultado da união de várias ciências da saúde e nucleares, cuja ferramenta principal de estudo são os radiofármacos. Os radiofármacos são compostos formados por um radioisótopo e um fármaco (LUIZ; BRANDÃO; BATISTA, 2011). O fármaco tem afinidade química pelo local do corpo onde há a atuação do radiofármaco, por isso ele funciona como uma espécie de substrato para o radioisótopo, transportando-o para o seu local de atuação (PUJATTI, 2012). Já o radioisótopo possui seu núcleo instável, e que por conta dessa instabilidade energética acaba emitindo determinados tipos de radiação como a gama para voltar ao estado estável (LUIZ; BRANDÃO; BATISTA, 2011). Por conta dessa propriedade, o radioisótopo é o responsável pela ação diagnóstica ou terapêutica do radiofármaco (PUJATTI, 2012).

Os radiofármacos são utilizados pela Medicina Nuclear no tratamento de diversas doenças, principalmente em casos de câncer (SANTOS; BOLOGNESI, 2014). Podemos ver como exemplo o seu uso em metástases ósseas, câncer de mama e próstata, enfermidades que produzem dores intensas, mas que podem ser aliviadas de $40 \%$ a $80 \%$ após o uso destes (PRADO et al., 2014). A radiação emitida pelo radioisótopo permite o diagnóstico precoce, antes que alterações anatômicas e fisiológicas surjam, sendo bastante relevante para doenças como o câncer (SOBRAL, 2016). Outro fator relevante é a alta sensibilidade mesmo em baixas concentrações (ROBILOTTA, 2006; COUTO, 2014).

A terapia radionuclídica, na teoria, apresenta vantagens em relação à convencional, haja vista que a administração de radiofármacos em certas terapias permite o uso de elevadas doses de radiação sem causar o aumento dos níveis de toxicidade em tecidos saudáveis(UNAK, 2002).

Tendo em vista que no ano de 2018 cerca de dois milhões de procedimentos envolvendo radiofármacos no Brasil, verificou a necessidade de compreender os métodos disponíveis para o tratamento de tumores e outras patologias. Portanto, o objetivo deste trabalho foi elencar as principais aplicações terapêuticas dos radiofármacos no diagnóstico e tratamento de tumores malignos.
\end{abstract}

\section{MATERIAIS E MÉTODOS}

Esta revisão da literatura dissertativa teve como base a pesquisa de artigos científicos e trabalhos acadêmicos. Como critérios de inclusão: foram pesquisados artigos dos últimos 5 anos, em português, salvo artigos excepcionais. A coleta de dados foi através dos portais Google acadêmico e Scielo. Tendo como escolha dos descritores: radiofármacos, radioisótopos, medicina nuclear e terapia radionuclídica. Como critério de exclusão: artigos em inglês, e os quais no resumo não fosse encontrado suas aplicações terapêuticas.

\section{RESULTADOS E DISCUSSÃO}

Histórico da utilização de radiofármacos no Brasil No Brasil os primeiros passos no estudo dos radiofármacos começaram a partir de 1956, quando, através do convênio entre o Conselho Nacional de Pesquisa (CNPq) e a Universidade de São Paulo. Através deles foi criado o Instituto de Energia Atômica (IEA), hoje chamado de Instituto de Pesquisas Energéticas e Nucleares (IPEN), órgão que é gerenciado administrativa, técnica e financeiramente pela Comissão Nacional de Energia Nuclear (CNEN) (SILVA, 2002). Os trabalhos pioneiros no campo dos radioisótopos, iniciaram no IPEN, com a produção e uso médico do lodo-131, com finalidades terapêuticas e diagnósticas de doenças, mas apenas em 1963 a produção de radioisótopos se tornou constante, e continua assim até os dias atuais, sendo feita a produção completa do radiofármaco (LUIZ; BRANDÃO; BATISTA, 2011).

Em 2018 o Brasil, através do IPEN, fabricou 38 radiofármacos - dos gerados em reatores, como o lodo-131, aos processados no cíclotron, como a fluorodesoxiglicose (FDG, ou flúor-18) e o tálio (TL-201).

\section{Classificação dos radiofármacos}

Segundo a Organização Mundial de Saúde (OMS), os radiofármacos podem ser classificados nas seguintes categorias (World Health Organization, 2004): (a) Produtos radioativos prontos para uso; (b) Geradores de radionuclídeos; (c) Componentes não radioativos (reagentes liofilizados) para preparação de compostos marcados com elementos radioativos; (d) precursores utilizados para marcação de outras substâncias antes da administração.

Os radiofármacos prontos para uso são aqueles que já contém em sua composição um radioisótopo viável de uso imediato, o qual é parte integrante da aplicação medicinal da preparação, tornando-a apropriada para algumas aplicações de diagnóstico ou terapias (ALVES; GIORGIS; ARAÚJO, 2013). Os radiofármacos geradores de radionuclídeos compõem-se em um sistema no qual um radionuclídeo "filho" (que possui um curto tempo de meia-vida) é separado de um radionuclídeo "pai” pelo processo de eluição (separação, fracionamento de uma mistura de partículas) ou por outro meio, e, posteriormente, é utilizado na preparação de radiofármacos (ALVES; GIORGIS; ARAÚJO, 2013). E os componentes não radioativos (kits) em geral correspondem a um frasco contendo os componentes não radioativos de uma preparação radiofarmacêutica, geralmente sob a forma esterilizada, que devem ser recompostos ou combinados com um radioisótopo para a síntese do radiofármaco antes de serem administrados ao paciente (ALVES; GIORGIS; ARAÚJO, 2013).

\section{Radiofármacos com finalidade diagnóstica}

Os radiofármacos que são usados com finalidade diagnóstica são classificados como de perfusão e específicos. Na sua composição são utilizados radioisótopos como $0{ }^{123} \mathrm{I},{ }^{111} \mathrm{In},{ }^{68} \mathrm{Ga}$, ${ }^{201} \mathrm{~T}$, que são emissores de radiação gama, cuja onda eletromagnética possui alta 
penetrabilidade tecidual e um menor poder de ionização (PRADO et al., 2014). Enquanto os radiofármacos de perfusão, também chamados de primeira geração, são transportados pelo sangue e não possuem locais específicos para ligação e atingem o alvo através do fluxo sanguíneo, os radiofármacos específicos, ou de segunda geração, são conduzidos por biomoléculas ativas, que possuem afinidade para receptores celulares e podem ser usadas tanto para fins diagnósticos como para terapia (IAEA, 2008).

Depois de ser absorvido pela circulação sanguínea, o fármaco pode se ligar em diversas proporções a proteínas plasmáticas. A parte do fármaco não ligado passa através das membranas, onde fica com disponibilidade de ligações com receptores, causando assim o efeito farmacológico desejado. 0 complexo fármaco-proteína atua como reservatório na circulação sanguínea, prolongando a chegada do fármaco aos sítios de eliminação e consequentemente, aos órgãos alvo. Por fim, a interação com proteínas pode influenciar diretamente na meia vida biológica do fármaco, da mesma forma que a interação das proteínas do plasma causa impacto diretamente na biodistribuição dos radiofármacos aos órgãos de interesse (KHOJASTEH; WONG; HOP, 2011).

Os radiofármacos com função diagnóstica são utilizados na obtenção de imagens a partir da detecção da radiação proveniente do paciente (PRADO et al., 2014). O procedimento, não invasivo, possibilita avaliações anatômicas, morfológicas e funcionais, e as técnicas utilizadas para a aquisição de imagens são a tomografia e a cintilografia, as quais são obtidas através de sistemas de detecção sensíveis às radiações gama emitidas pelos radiofármacos, que se concentram nos órgãos ou tecidos de interesse, permitindo o estudo metabólico e funcional de tais órgãos (BOMBARDA; JUNIOR; FILHO, 2002).

Em tecidos tumorais, existem várias alterações bioquímicas, tais como elevadas taxas de glicólise aeróbia e anaeróbia quando comparadas com as encontradas em tecidos normais, e por conta disto alguns radiofármacos tem como objetivo se ligar a receptores e identificar as alterações na concentração dos mesmos em nestes tecidos biológico. Assim, quando o paciente toma uma glicose marcada com flúor, ela se concentra no local onde está sendo gasta mais energia, o que indica uma grande concentração de células tumorais, por conta de as mesmas apresentarem fisiologia e taxa metabólica alterada, consumindo mais energia (PRADO et al., 2014).

\section{Terapia radioisotópica}

A terapia radioisotópica foi desenvolvida para transportar uma dose de radiação terapêutica por via intravenosa até sítios ativos específicos, como o das células tumorais (SOBRAL, 2016). Nesses radiofármacos são utilizados radioisótopos que emitem radiação particulada a ou $\mathrm{B}^{-}$, pois possuem pouco poder de penetração mas com muita energia, e dessa maneira, essas partículas podem danificar organelas celulares e causa a morte de células tumorais de forma direta através da quebra do seu DNA ou de forma indireta, por via de radicais livres como peróxido de hidrogênio (CHEN et al., 2008).

Alguns avanços nas áreas de biologia nuclear mostraram marcadores radioativos para alguns neurotransmissores como acetilcolina, serotonina, nicotina e o GABA (COSTA; OLIVEIRA; BRESSAN, 2001). 0 GABA é mantido como o principal neurotransmissor inibitório do Sistema Nervoso Central (SNC), causando uma hiperpolarização ao ativar seus receptores, e é um regulador da função neuronal présináptico de grande importância (BLOOM,1996; KORPI et al.,2002). É obtido através da enzima glutamato-descarboxilase (GAD) e de uma descarboxilação do L-glutamato, sobre catabolização pela GABA-transaminase (GABA-T) e por transaminação em semialdeído (STAHL, 2002; TREVOR, 1998). Este neurotransmissor tem seus efeitos estudados pela interação entre dois tipos diferentes de receptores: GABA-1, que está presente nos canais iônicos de cloro (Cl), e possui o objetivo de aumentar a condução de cloro nos neurônios pré-sinápticos; e GABA-2, cuja atuação é na proteína Gintracelular, causando um aumento na condução de canais de potássio associados (BLOOM,1996).

Os efeitos biológicos provenientes da radiação dependem de vários fatores, como a sensibilidade do tecido alvo e a dose que é absorvida. Estes efeitos acontecem em decorrência de alterações na molécula de DNA que impedem que a replicação celular ocorra, existindo a possibilidade de que essas modificações sejam transmitidas as próximas gerações celulares (CEMBER, 2009). 0 efeito da radiação na molécula de DNA pode ser dividido em ação direta e indireta. Na ação direta, o DNA interage com a radiação, levando a uma alteração da molécula, enquanto que na ação indireta a interação da radiação ionizante ocorre primeiro com a molécula de água, onde se originam produtos com alta toxicidade que provocam lesões na molécula de DNA (BUSHONG, 2008).

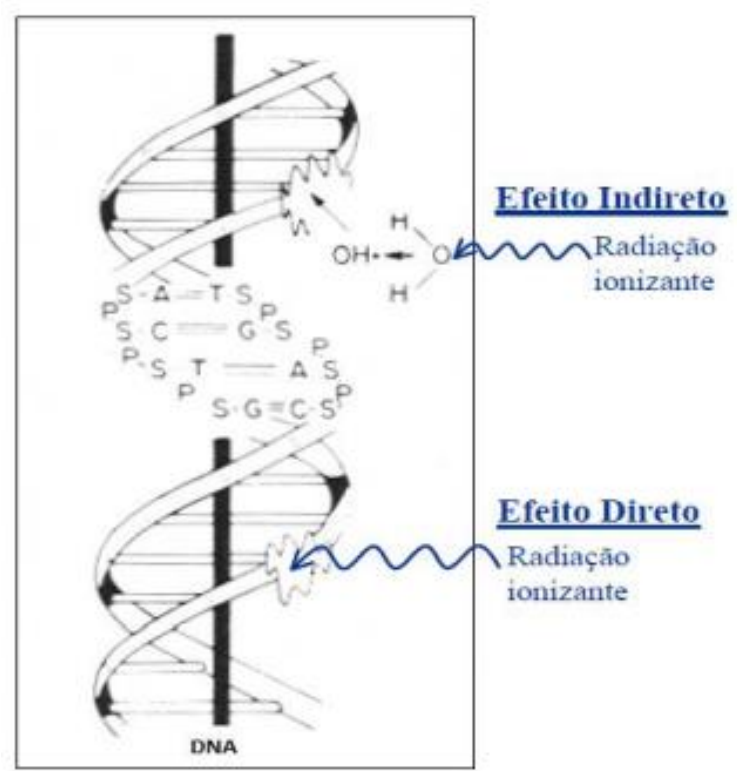

Figura 1. Interação direta e indireta da radiação com o DNA (Fonte: Fernandes, 2005).

Como qualquer medicamento, quando o radiofármaco é administrado ele sofre um processo chamado biotransformação, que abrange a distribuição, metabolização e excreção (OLIVEIRA, 2006). Existem diversos mecanismos pelos quais um radiofármaco se liga ao seu sitio ativo, como por exemplo a perfusão sanguínea do composto pelo órgão alvo ou até a participação em uma via metabólica (VALLABHAJOSULA, 2009).

Existem alguns fatores que podem comprometer a ligação de radiofármacos e seus receptores, como por exemplo depuração plasmáticas, onde os compostos para ligação são de tamanho pequeno e facilmente eliminados na circulação sanguínea, uma vez que os receptores dispõem de baixa concentração (VALLABHAJOSULA, 2001, apud OLIVEIRA et al., 2006, p.155).

$O$ uso invasivo tem sido um importante aliado no tratamento de patologias como o câncer, visto que o radiofármaco é depositado no órgão ou tecido alvo, e é absorvido apenas pelas células cancerígenas, liberando radiação para eliminá-las (BOMBARDA; JUNIOR; FILHO, 2002).

Especificidades e cuidados relacionados ao uso de radioisótopos Para a utilização de um radionuclídeo em terapias, algumas características químicas e físicas devem ser analisadas primeiramente, como a emissão de radiação corpuscular (SANTOS; 
BOLOGNESI, 2014). Ele também deve apresentar baixa captação inespecífica, ou seja, deve ser captado apenas pelas células alvo, e dessa maneira assegurar uma dosimetria irrelevante nos demais tecido do organismo (SANTOS; BOLOGNESI, 2014). Os elementos radioativos apresentam afinidade e especificidade por diferentes órgãos, sistemas ou patologias, e as suas características físicas determinam "o tipo de emissão nuclear, o tempo de meia-vida e a energia das partículas e/ou radiação eletromagnética emitida" (OLIVEIRA, et al., 2006, p.152)

A aplicação de radiofármacos pode desencadear no organismo humano a mesma taxa de radioatividade que quando o indivíduo é exposto a radiação ionizante, principalmente durante a fase reprodutiva, onde a células se replicam com certa frequência e são mais vulneráveis aos efeitos da radioatividade, onde os principais efeitos causados podem ser anemia, leucopenia, neoplasia e inflamação cutânea (MARTINDALE, 2005). Por isso, é importante que o radioisótopo seja excretado de forma rápida após a sua metabolização, e deve possuir pouca afinidade ao sangue e aos tecidos saudáveis do corpo. (SRIVASTAVA; DADACHOVA, 2001). Eles são eliminados do organismo através da excreção renal e biliar, e o seu desaparecimento ocorre pelo decaimento físico do radionuclídeo, buscando-se sempre um meio termo com relação ao tempo de meia-vida, que deve ser o mais curto possível, de forma a minimizar a exposição do paciente à radiação, mas suficientemente longo para a aquisição e processamento das imagens (PRADO et al., 2014).

A terapia também envolve etapas como a escolha do radioisótopo e a substancia a ser radiomarcada (ZALUTSKY, 2003). A tabela 1 a seguir mostra alguns dos radioisótopos que são mais utilizados no tratamento de tumores.

Tabela 1. Principais radioisótopos utilizados em diagnósticos e/ou tratamento de tumores

\begin{tabular}{|c|c|}
\hline Radioisótopo & Aplicações \\
\hline Flúor-18 $\left({ }^{18} \mathrm{~F}\right)$ & Metástase Tumoral \\
\hline Cromo-51 $\left({ }^{51} \mathrm{Cr}\right)$ & Tumores intestinais \\
\hline Gálio-68 $\left({ }^{68} \mathrm{Ga}\right)$ & Tecidos moles \\
\hline Tecnécio $\left({ }^{99 \mathrm{~m}} \mathrm{Tc}\right)$ & $\begin{array}{c}\text { Cérebro, glândulas salivares, sistema } \\
\text { ósseo, coração, estômago, rins, pulmão } \\
\text { e fígado }\end{array}$ \\
\hline lodo-131 $\left({ }^{131} \mathrm{I}\right)$ & Tireoide, fígado e rins \\
\hline
\end{tabular}

\section{CONCLUSÕES}

Observou-se que o desenvolvimento das aplicações da Medicina Nuclear em diversas áreas médicas aumentou consideravelmente o número de possibilidades terapêuticas utilizando as propriedades dos radioisótopos. Em menos de um século, já é notável uma grande evolução, com extensos avanços nas áreas de diagnóstico e terapia, permitindo que um considerável percentual de portadores de doenças radiosensíveis tenha maiores chances de cura ou pelo menos um significativo aumento na qualidade de vida.

\section{REFERÊNCIAS}

BARABÁS, Roberta de Carvalho. Neurociências aplicadas ao ensinoaprendizagem da tecnologia nuclear. 2018. Tese (Doutorado em Tecnologia Nuclear - Reatores) - Instituto de Pesquisas Energéticas e Nucleares, Universidade de São Paulo, São Paulo, 2018. Disponível em: <http://www.teses.usp.br/teses/disponiveis/85/85133/tde29112018-075151/>. Acesso em: 2019-03-08.

BENEDETTO, Raquel. 89Zr-Imuno-PET/111In-Imuno- SPECT: desenvolvimento radiofarmacêutico de agentes de imagem molecular para receptores EGF. 2017. Tese (Doutorado em
Tecnologia Nuclear - Aplicações) - Instituto de Pesquisas Energéticas e Nucleares, Universidade de São Paulo, São Paulo, 2017. Disponível em: < http://www.teses.usp.br/teses/disponiveis/85/85131/tde16022018-150129/pt-br.php>.doi:10.11606/T.85.2018.tde16022018-150129. Acesso em: 2019-03-08.

CARAMELO, Francisco et al. A Radiação: Má ou Boa. Revista Internacional em Língua Portuguesa, Coimbra, Portugal, 2018. Disponível em: https://www.researchgate.net/publication/329383502_A_Radiacao _Ma_ou_Boa. Acesso em: 11 mar. 2019.

LUIZ, Leandro da Conceição; BRANDÃO, Diana Lourenço; BATISTA, Rafaela Tavares. Avaliação de um Grupo de Profissionais de Saúde Sobre os Conceitos Físicos e Toxicológicos dos Radiofármacos que Utilizam os Radioisótopos 123I e 131l. Physicae, [S.l.], p. 13, mar. 2013. ISSN 22363521. Disponível em: <https://physicae.ifi.unicamp.br/index.php/physicae/article/view /physicae.10.4>. Acesso em: 29 mar. 2019. doi: https://doi.org/10.5196/physicae.10.4.

SANTOS, Cristofer Alan Costa; BOLOGNESI, Leandro. Aplicações Terapêuticas em Medicina Nuclear. Tekhne e Logos, Botucatu, SP, dez $2014 . \quad$ Disponível em: http://www.fatecbt.edu.br/seer/index.php/tl/article/view/270. Acesso em: 5 mar. 2019.

SOBRAL, Danielle Vieira. Síntese e avaliação da interação de peptídeos radiomarcados com células tumorigênicas. Relevância para o estudo de glioblastoma. 2016. Dissertação (Mestrado em Ciências da Saúde) - Faculdade de Ciências Médicas da Santa Casa de São Paulo, São Paulo, SP, 2016. Disponível em: http://www.fcmsantacasasp.edu.br/wpcontent/uploads/dissertacoes-e-teses/ciencias-dasaude/2016/Mestrado-Academico/2016-Danielle-Vieira-SobralMA.pdf. Acesso em: 14 mar. 2019. 